\title{
RETROSPECTIVE ANALYSIS AND MODERN TENDENCIES OF SWIMMERS' MOVEMENT TECHNIQUE DEVELOPMENT AT DIFFERENT STAGES OF MANY YEARS SPORTS TRAINING
}

(C) 2016

M.A. Vershinin, doctor of pedagogical sciences, professor of the Chair of Theory and Methods of Physical Education M.V. Pinyasova, postgraduate student of the Chair of Theory and Methods of Physical Education Volgograd State Physical Education Academy, Volgograd (Russia)

Abstract. Based on retrospective analysis of scientific-methodical literature the article deals with the analysis of trends of swimmers' movement technique development at different stages of many year sports training. The authors describe the movement technique in swimming with basic concepts of biomechanical and fluid mechanics. Kinematical characteristics including spatial-temporal, temporal and spatial parame-ters of the athlete's movements are investigated. This article considers the dynamics of change of such indicators of technical readiness as rhythm and the stroke rate at different stages of swimmers sport training. Based on data analysis of specialized literature the authors concluded that on the initial stages of sports training swimmers' results increase due to the change in the length of step and at the stage of higher sports skill by changing of stroke rate. The authors study the age dynamics of step length and tempo at the initial training, initial and advanced specialization formation which takes place in three stages: 1) mastering the technique of swimming at optimal amplitude; 2) gradual stretching, the elonga-tion step; 3) search for optimum correlation between stride length and tempo. On the basis of study of step length growth of young athletes aged $9-15$ years, the authors conclude that rhythm-based tech-nology course in swimming is generated starting from the initial stage of long-term preparation.

Keywords: swimming; technique of movements in swimming; stages of sports training; swimmers' sports training; swimmers' motor actions technique development; step length; stroke rate.

УДК 37.01

\section{СПЕЦИФИКА ОБУЧЕНИЯ И ВОСПИТАНИЯ УЧАЩИХСЯ В УСЛОВИЯХ ПОЛИЭТНИЧЕСКОЙ ОБРАЗОВАТЕЛЬНОЙ СРЕДЫ}

(C) 2016

Е.А. Зайцева, кандидат филологических наук, доцент кафедры поликультурного образования

A.B. Нуждин, кандидат педагогических наук, заведующий кафедрой поликультурного образования Самарский областной институт повышения квалификации и переподготовки работников образования, Самара (Россия)

Аннотащия. Одной из важных задач современного российского образования является подготовка человека к эффективной деятельности и общению в поликультурной среде. Различные аспекты поликультурного образования нашли отражение во многих нормативно-правовых документах Российской Федерации. Содержание межкультурной компетентности педагога связано с такими аспектами, как осознание национальнорелигиозных, гендерных и иных особенностей обучающихся, уважительное отношение к ним; способность к культуросообразному поведению; способность организовать конструктивное межкультурное взаимодействие в коллективе и использовать межкультурные различия для обогащения личного культурного опыта обучающихся; знание и учет психологических особенностей восприятия и поведения обучающихся, обусловленных их культурной принадлежностью; способность обеспечивать поликультурную направленность учебновоспитательного процесса, прогнозировать, предупреждать и разрешать межкультурные конфликты в коллективе и т.д. Работа по изучению культуры и традиций разных национальностей в школе должна проходить по разным направлениям: изучение истории народностей и истории присоединения тех или иных народов к России, рассказ о вкладе той или иной этнической группы в защиту своего Отечества; участие детей в национальных и религиозных праздниках; изучение национальной культуры народов (костюма, обычаев, традиций); чтение литературных произведений национальных поэтов и писателей; проведение дней национальных культур; разучивание народных игр; совместные дела класса, школы (конкурсы, соревнования, игры, проекты); работа с семьей, организация семейных вечеров, во время которых поют национальные песни, исполняют стихи на родном языке, предлагают попробовать национальные блюда, рассказывают о семейных и национальных традициях; проведение тренинговых упражнений по воспитанию толерантности и т.д.

Ключевые слова: полиэтническая образовательная среда; поликультурная образовательная среда; поликультурное образование; межкультурная компетентность; культурное многообразие; толерантность; этнопедагогика; этнопедагогические традиции; национальные культуры.

Проблемы образования и воспитания детей в полиэтническом обществе актуальны сегодня во всем мире, поэтому концепции поликультурного образования постепенно завоевывают мировое образовательное пространство. Одной из важных задач современного российского образования яв- ляется подготовка человека к эффективной деятельности и общению в поликультурной среде, что связано с осознанием культурного многообразия, толерантным отношением к этому многообразию и способностью к культуросообразному поведению. 
Образованию сегодня отводится ключевая роль 8 духовно-нравственной консолидаџии российского общества; в утверждении «многообразия культур и народов»; в утверждении «межэтнического мира и согласия» [1, с. 8]. Под многообразием культур и народов в «Кониепции духовно-нравственного развития и воспитания личности гражданина России $(Ф Г О С) »$ понимается «культурное многообразие, существующее в стране и в мире в целом. Для России это существование, диалог и взаимообогащение всех культурных потоков (или слоев): общенациональной, общероссийской культуры на основе русского языка, этнических культур многонационального народа Российской Федерации и глобальных или мировых культурных явлений и систем. Культурное многообразие и свобода культурного выбора являются условием развития, стабильности и гражданского согласия»; под межэтническим миром и согласием «единство в многообразии, признание и поддержка культур, традиций и самосознания всех представителей многонационального народа Российской Федерации, гарантированное равноправие граждан независимо от национальности, а также политика интеграции, предотвращения напряжённости и разрешения конфликтов на этнической или религиозной основе. Межэтнический мир включает политику толерантности, то есть признания и уважения культурных и других различий среди граждан страны и проживающих в ней граждан других стран» $[1$, с. 8].

Основными принципами поликультурного образования считаются: полилингвальность, преемственность, дифференциация и разнообразие, креативность, культурная целостность, объемная (стереоскопическая) картина мира, вариативность, этическая актуальность [2].

Федеральный государственный образовательный стандарт начального общего образования направлен на обеспечение: «...сохранения и развития культурного разнообразия и языкового наследия многонационального народа Российской Федерации, права на изучение родного языка, возможности получения начального общего образования на родном языке, овладения духовными ценностями и культурой многонационального народа России» [3]. Личностные результаты освоения основной образовательной программы начального общего образования «должны отражать:

1) формирование основ российской гражданской идентичности, чувства гордости за свою Родину, российский народ и историю России, осознание своей этнической и национальной принадлежности; формирование ценностей многонационального российского общества; становление гуманистических и демократических ценностных ориентаций;

2) формирование целостного, социально ориентированного взгляда на мир в его органичном единстве и разнообразии природы, народов, культур и религий;

3) формирование уважительного отношения к иному мнению, истории и культуре других народов...» [3].

В списке личностных характеристик выпускника основной школы, согласно Федеральному государственному образовательному стандарту основного общего образования, находим следующие характеристики:

1) любящий свой край и своё Отечество, знающий русский и родной язык, уважающий свой народ, его культуру и духовные традиции;

2) осознающий и принимающий ценности человеческой жизни, семьи, гражданского общества, многонационального российского народа, человечества [4].

В Профессиональном стандарте педагога в число трудовых действий педагога включены следующие: 1) формирование толерантности и навыков поведения в изменяющейся поликультурной среде; 2) создание позитивного психологического климата в группе и условий для доброжелательных отношений между детьми, в том числе принадлежащими к разным национально-культурным, религиозным общностям и социальным слоям, а также с различными (в том числе ограниченными) возможностями здоровья; 3) применение специальных языковых программ (в том числе русского как иностранного), программ повышения языковой культуры и развития навыков поликультурного общения. Среди необходимых знаний педагога выделяется знание методов и технологий поликультурного, дифференцированного и развивающего обучения. Среди необходимых умений педагога выделяется проявление позитивного отношения к местным языковым явлениям, отражающим культурно-исторические особенности развития региона; проявление позитивного отношения к родным языкам обучающихся [5].

Цели и задачи Федеральной иелевой программы «Укрепление единства российской нащии и этнокультурное развитие народов России (2014-2020 го$\partial b l) »$ заключаются в укреплении единства многонационального народа Российской Федерации (российской нации); в содействии укреплению гражданского единства и гармонизации межнациональных отношений; в содействии этнокультурному многообразию народов России. Учебный прочесс в каждом конкретном учреждении должен строиться с учетом особенностей культуры своего региона, способствовать сохранению этнокультурных ценностей народов России. Школа призвана обеспечить учащимся возможность приобщения, с одной стороны, к общечеловеческим знаниям и ценностям, с другой - к богатству и самобытности национальной культуры [6].

Вот далеко не полный перечень нормативноправовых документов, отражающих различные аспекты российского поликультурного образования сегодня. Российская Федерация является одним из крупнейших государств мира с полиэтническим составом населения. В России проживают представители 193 народов (по данным Всероссийской переписи населения 2010 года), обладающих отличительными особенностями материальной и духовной культуры. Культурное и языковое многообразие российских народов защищено государством. В России используется 277 языков и диалектов, в системе государственного образования используется 89 языков, из них 30 - в качестве языка обучения, 59 - в качестве предмета изучения [6].

С.К. Жидкова отмечает, что, по данным переписи населения 1989 года, этнический состав населения городов Самарской области представлен более чем 
100 национальностями, но публикуются сведения только по 11 из них (русским, украинцам, белорусам, казахам, башкирам, марийцам, мордве, татарам, чувашам, евреям и немцам), количество остальных указано одной цифрой под названием «другие национальности» [7, с. 36]. Этнический состав населения Самарской области, по данным Всероссийской переписи населения 2010 года, насчитывает 121 группу национальностей и 14 этнических подгрупп. В числе наиболее многочисленных национальностей Самарской области по-прежнему отмечены: русские, украинцьь, белорусы, казахи, башкиры, марийць, мордва, татары, чуваши, евреи, немцы [8, с. 13].

Таким образом, подготовка педагога к эффективной деятельности в условиях поликультурной образовательной среды, формирование и развитие у него межкультурной (полиэтнической, этнопедагогической) компетентности - важные задачи, стоящие перед нашим государством и системой образования [9]. Как справедливо отмечает Г.Д. Дмитриев, именно будущим учителям особенно важно «уметь работать с различными в культурном отношении людьми, правильно понимать человеческие различия, быть толерантными к ним, уметь утверждать своими личными делами и словами культурный плюрализм в обществе» [10, с. 116]. Поэтому содержание межкультурной компетентности педагога должно быть шире, чем у иных граждан: специалисты данной сферы должны не только уметь жить в поликультурной среде, взаимодействовать с ее представителями, но и быть активными «проводниками» идей культурного плюрализма, осуществлять поликультурное воспитание учащихся.

Профессиональное содержание межкультурной компетентности педагога связано с такими аспектами, как:

1) осознание национально-религиозных, гендерных и иных особенностей обучающихся, уважительное отношение к ним;

2) способность к культуросообразному поведению;

3) способность организовать конструктивное межкультурное взаимодействие в коллективе и использовать межкультурные различия для обогащения личного культурного опыта обучающихся;

4) знание и учет психологических особенностей восприятия и поведения обучающихся, обусловленных их культурной принадлежностью;

5) способность обеспечивать поликультурную направленность учебно-воспитательного процесса, прогнозировать, предупреждать и разрешать межкультурные конфликты в коллективе и т.д.

А.М. Хупсарокова и Ф.П. Хакунова определяют поликультурную компетентность педагога как интегративное личностно-профессиональное качество, обусловливающее его способность эффективно участвовать в социальных процессах поликультурного общества, осуществлять межкультурное взаимодействие, учитывать поликультурный состав субъектов профессиональной деятельности и использовать его характеристики и особенности для решения педагогических задач, а также осуществлять поликультурное воспитание учащихся [11].

В полиэтнических классах учитель часто сталкивается с нестандартными ситуациями, каждая из ко- торых требует от него специфического подхода и решения [12; 13]. Поэтому в деятельности педагога особое значение приобретает умение быстро ориентироваться, правильно оценивать сложившуюся обстановку и принимать решения, имеющие необходимое воспитательное значение. Это становится возможным, если учитель в общении с людьми разных национальностей умеет выслушать и высказать свою точку зрения, участвуя в обсуждении национальноэтических проблем, проявляет такт в оценке исторических событий, обрядов, традиций других народов, хорошо знает историко-культурное наследие народов, проживающих в крае, а также владеет основными методами и формами работы в полиэтнической образовательной среде [14; 15].

Осуществляя свою профессиональную деятельность, педагог должен исходить из того, что формирование и развитие растущей личности происходит в среде, насыщенной проявлениями различных культур, и подчас на пересечении ряда этнопедагогических традиций, носителями которых являются семьи, отдельные индивиды, этнические сообщества, искусственная природа, средства массовой информации [16, с. 395]. Люди различных культурных групп имеют характеристики, которые делают их схожими, создают одну человеческую расу. Однако, попадая в другую культуру, человек часто обращает внимание прежде всего на различия. Учителю в своей работе необходимо учитывать, что культурные отличия, как уникальная черта каждого человека, перестают быть источником конфликта, если они рассматриваются в качестве одной из альтернатив человеческого бытия [10, с. 19].

Сегодня очевиден дефицит педагогического внимания к воспитательному потенциалу этнопедагогических традиций, определяющих, по сути, процесс социализации детей и подростков, игнорирование или формальный учет того факта, что в современной образовательной действительности становление личности происходит на границах пересекающихся этнокультурных образцов. Этнопедагогика «изучает процесс социального взаимодействия и общественного воздействия, в ходе которого воспитывается, развивается личность, усваивающая социальные нормы, ценности, опыт; собирает и систематизирует народные знания о воспитании и обучении детей, народную мудрость, отраженную в религиозных учениях, сказках, сказаниях, былинах, притчах, песнях, загадках, пословицах и поговорках, играх, игрушках и пр., в семейном и общинном укладе, быте, традициях, а также философско-этические, собственно педагогические мысли и воззрения, то есть весь педагогический потенциал, оказывающий влияние на процесс историко-культурного формирования личности» $[17$, с. 4$]$.

Как отмечает О.Н. Голышева, на всех этапах работы с коллективом, где представлены разные национальности, независимо от возраста учащихся, необходимо продумать практические меры, чтобы детям было легче преодолеть в себе национальную замкнутость, эгоизм, а наоборот, ориентироваться на повышение культуры всего ученического коллектива, использовать его возможности для противодействия вредным националистическим влияниям. При орга- 
низации работы по воспитанию толерантности педагогам необходимо знать и учитывать: национальный состав коллектива учащихся; проблемы в отношениях между детьми и их причины; этнопедагогические и этнопсихологические особенности культуры, под воздействием которой складываются межнациональные отношения среди учащихся в семьях [18, с. 337].

Несомненную ценность для учащихся имеют этнографические знания о происхождении народов, с которыми они вместе учатся, о своеобразии национального этикета, обрядов, быта, одежды, самобытности, искусства, художественных промыслов, праздников. Важно, чтобы педагог проявлял компетентность во время посещения учащимися краеведческих и литературных музеев, различных национальных культурных центров, театров, выставок, фольклорных концертов, просмотров фильмов национальных студий и т.д.

Большие возможности в поликультурном воспитании обучающихся заключаются в использовании потенциала учебного прочесса. При изучении различных учебных предметов педагог должен приводить примеры тех или иных явлений из культур тех народов, представители которых находятся в классе. Такой подход имеет двоякую направленность. Услышав на занятии упоминание о родной культуре, дети проникаются чувством гордости за нее. В то же время русские школьники, получив представление о другой культуре, начинают лучше понимать своих одноклассников, национально-психологические особенности их поведения, что способствует конструктивному диалогу между ними. Соответствующий материал может включаться в разные учебные предметы. Работая в классе с многонациональным составом учащихся, нужно помнить, что у каждого народа есть свои писатели, ученые, музыканты, певцы и художники, составляющие его национальную гордость, поэтому в необходимых случаях на уроке полезно на них сослаться.

Рассмотрим пути и способы реализации принцииа диалога культур на примере изучения литературных текстов. Задача учителя литературы заключается в том, чтобы организовать диалог культур посредством художественных текстов и удерживать диалогическую ситуацию на протяжении всего диалога, а главное - перенести его во внутренний диалог учащегося. Диалог культур при изучении литературных произведений может осуществляться одним из следующих путей (либо совокупностью нескольких):

1) интерпретацией художественного произведения в других видах искусства той культуры, представителем которой является учащийся, с целью знакомства с ней одноклассников в рамках изучения того или иного художественного произведения;

2) сопоставлением изучаемого художественного произведения, творчества писателя или периода развития литературы с образцами литературы, принадлежащей культуре учащегося (возможно расширение учебного материала за счет сопоставления с образцами поликультурного пространства в целом);

3) сопоставлением с образцами мировой литературы и интерпретациями художественного произведения в других видах искусства поликультурного пространства в целом;
4) нахождением в художественном произведении фундаментальных мировых образов, сюжетов и символов [19, с. 245].

Учебно-воспитательный процесс следует строить как взаимодействие представителей разных национальностей. При выполнении различных учебных заданий класс можно разбивать на разнонациональные группы. Школьники понимают, что учебные задачи могут решаться эффективно, если налажено внутригрупповое взаимодействие. Эффективны и задания, связанные с родной культурой учеников. Результативны и разного рода культурно-специфические тренинги и техники, предложенные Т.Г. Стефаненко. Это тренинги, включающие реальные межкультурные контакты; атрибутивные тренинги, в которых акцент делается на обучении тому, как представители различных народов и культур интерпретируют причины поведения и результаты деятельности; культурные ассимиляторы, которые называют также техникой повышения межкультурной сензитивноcmu. При организации процесса обучения учителю нельзя допускать предвзятого отношения к представителям одних национальностей и, наоборот, наделять привилегиями других. Ему следует всегда быть справедливым к каждому человеку, независимо от его национальной принадлежности. Воспитательная работа с многонациональным коллективом имеет свою специфику. Она направлена на сплочение коллектива и воспитание у обучаемых: 1) культуры межнационального общения; 2) толерантности; 3) нравственности (нравственное просвещение) и т.д. Успешность работы педагога в многонациональном коллективе во многом зависит от того, насколько он учитывает в своей деятельности религиозные чувства, специфику национальной психологии обучающихся, их национального самосознания [20, с. 466].

Таким образом, работа по изучению культуры и традиций разных национальностей, повышению уровня культуры межнационального общения в школе должна проходить по разным направлениям.

1. Углубленное изучение истории народностей и истории присоединения тех или иных народов к России. Рассказ о значительном вкладе той или иной этнической группы в защиту своего Отечества.

2. Участие детей в национальных и религиозных праздниках.

3. Изучение национальной культуры народов (костюма, обычаев, традиций).

4. Чтение произведений национальных поэтов и писателей.

5. Проведение дней национальных культур.

6. Разучивание народных игр.

7. Совместные дела класса, школы (конкурсы, соревнования, игры, проекты).

8. Работа с семьей, организация семейных вечеров, во время которых представители каждой семьи знакомят класс со своими профессиями, поют любимые национальные песни, исполняют стихи на родном языке, предлагают попробовать национальные блюда, рассказывают о семейных и национальных традициях.

9. Проведение тренинговых упражнений по воспитанию толерантности и т.д. 


\section{СПИСОК ЛИТЕРАТУРЫ:}

1. Концепция духовно-нравственного развития и воспитания личности гражданина России (ФГОС) / А.Я. Данилюк, А.М. Кодаков, В.А. Тишков. М.: Просвещение, 2009.

2. Концепция поликультурного образования в России [Электронный pecypc] // http://mon.gov.ru/ work/vosp/dok/6988.

3. Федеральный государственный образовательный стандарт начального общего образования [Электронный ресурс] // http://base.garant.ru/197127.

4. Федеральный государственный образовательный стандарт основного общего образования [Электронный ресурс] // http://window.edu.ru/catalog/pdf2txt/ 768/72768/50521

5. Педагог (педагогическая деятельность в сфере дошкольного, начального общего, основного общего, среднего общего образования) (воспитатель, учитель) [Электронный ресурс] // http://ug.ru/new standards/6.

6. Федеральная целевая программа Укрепление единства российской нации и этнокультурное развитие народов России (2014-2020 годы) [Электронный pecypc] // http://government.ru/media/files/41d4862001a d2a4e5359.pdf.

7. Жидкова С.К. Этнический состав городского населения Самарской области // Этнос и культура. Информационный вестник, 2002. № 2. С. 36-40.

8. Национальный состав населения Самарской области: Статист. сборник / Самарастат, 2013. 327 с.

9. Кайсарова А.В. Педагогические условия формирования этнопедагогической компетентности у студентов в процессе обучения в педвузе: автореф. дис. ... канд. пед. наук. Чебоксары, 2008. 22 с.

10. Дмитриев Г.Д. Многокультурное образование. М.: Народное образование, 1999. 208 с.

11. Хупсарокова А.М., Хакунова Ф.П. Предметносодержательные компоненты поликультурной компетентности педагога [Электронный ресурс] // http:// otherreferats.allbest.ru/pedagogics/00274620_0.html.

12. Назаренко Н.Н. Педагогические проблемы полиэтнической образовательной среды [Электронный pecypc] // http://studik.net/pedagogicheskie-problemypolietnicheskoj-obrazovatelnoj-sredy.
13. Нечаева Е.А. Подготовка педагога к профессиональной деятельности в мультикультурном коллективе учащихся: автореф. дис. ... канд. пед. наук. Калининград, 2008. 25 с.

14. Нуждин А.В. Межкультурная компетентность педагога в контексте современного образования // Известия Самарского научного центра Российской академии наук. Т. 17. № 1(3). С. 588-593.

15. Зайцева Е.А., Нуждин А.В. Особенности деловой коммуникации в полиэтнической образовательной среде // Известия Самарского научного центра Российской академии наук. Т. 17. № 1(5). С. 11081112.

16. Ершов В.А., Лельчицкий И.Д. Этнопедагогические традиции как фактор формирования межкультурной компетенции // Известия Академии педагогических и социальных наук. Миграция: проблемы и решения. Вып. 11. М.; Воронеж: Издательство Московского психолого-социального института. Издательство НПО «МОДЭК», 2007. С. 394-397.

17. Волков Г.Н. Этнопедагогика: учебник для студентов средних и высших педагогических учебных заведений. М.: Издательский центр «Академия», 1999. 168 c.

18. Голышева О.М. Воспитание толерантной культуры у учащихся через народные традиции различных этнических групп: чуваши, эрзяне, русские // Русский мир и духовное развитие народов Поволжья. Самара: ООО «Книга», 2011. С. 334-338.

19. Житлевский Б.Б. Уроки литературы в полиэтнических классах: диалог культур // Русский язык в контексте межкультурной коммуникации: материалы международной научно-практической конференции, посвященной 90-летию со дня рождения профессора Е.М. Кубарева. Самара: ПГСГА,2011. С. 242-248.

20. Хайруллин Р.3. Социально-педагогическая адаптация студентов-мигрантов в условиях столичного мегаполиса // Известия Академии педагогических и социальных наук. Миграция: проблемы и решения. Вып. 11. М.; Воронеж: Издательство Московского психолого-социального института. Издательство НПО «МОДЭК», 2007. С. 458-468.

\section{PECULIARITIES OF TEACHING AND EDUCATING STUDENTS IN MULTIETHNIC EDUCATIONAL ENVIRONMENT}

\section{E.A. Zaitseva, candidate of philological sciences, associate professor of the Chair of Multicultural Education A.V. Nuzhdin, candidate of pedagogical sciences, head of the Chair of Multicultural Education Samara Regional Institute for Teachers Retraining and Staff Development in Education, Samara (Russia)}

Abstract. One of the main aims and objectives of Modern Russian education is to make a human be ready for effective working and interacting in the multiethnic educational environment. Different aspects of the multiethnic education are registered in numerous Legal Acts of the Russian federation. Educators' multiethnic competence comprises such aspects as knowing national, religious, gender and other peculiarities of students under training, respective attitude towards them; the ability to behave in terms of cultural conformity as well as the ability to organize meaningful dialogue in a multiethnic group and to use these cultural peculiarities to enrich students' personal experience. Moreover, educators' multiethnic competence also includes understanding of students' ethnopsychological reactions which are conditioned by their cultural background and national identity. The trainee has to anticipate and to resolve a conflict in a multiethnic group. Cultural studies of different nationalities have to be organized in different ways: among the most popular methods we are bound to mention the historical studies of nations and the annexation of different ethnic communities to the Russian federation, the history of an ethnic group contribution to the heroic deeds during wars and while defending the homeland. One of the most effective ways of understanding and assimilating other people's traditions and customs is to make students participate in different national festivals, religious holidays and feasts. 
Reading national poets and writers contributes greatly to the better acquisition of the material as well. There are some other methods to get acquainted with cultures for example, National days, learning national games, songs, poems; collective projects, competitions, contests; work with families and family celebrations of national holidays with national food, family stories about strong family traditions and customs; training exercises which cultivate students' tolerance towards other nations and ethnic groups etc.

Keywords: multiethnic educational environment; multicultural educational environment; multicultural education; intercultural competence; cultural diversity; tolerance; ethnic education; national cultures.

\title{
УДК 37.013
}

\section{ОБЩЕМЕТОДОЛОГИЧЕСКИЕ АСПЕКТЫ СТИМУЛИРОВАНИЯ САМОРАЗВИТИЯ ИНФОРМАЦИОННО-КОММУНИКАЦИОННОЙ КОМПЕТЕНТНОСТИ СТУДЕНТА В СИСТЕМЕ СРЕДНЕГО ПРОФЕССИОНАЛЬНОГО ОБРАЗОВАНИЯ}

\author{
(C) 2016 \\ Е.В. Замара, преподаватель информационных технологий \\ Самарский государственный колледж сервисных технологий и дизайна, Самара (Россия)
}

\begin{abstract}
Аннотаџия. В данной статье рассматривается общеметодологические аспекты стимулирования саморазвития информационно-коммуникационной компетентности студента в системе среднего профессионального образования, в том числе по специальности СПО 43.02.10 Туризм, которые связаны с личностным образованием будущих специалистов, обладающих информационно-коммуникационной компетентностью, стремлением к творческой реализации в информационно-образовательной среде и готовностью к работе в информационной среде. В статье описываются основные положения и значимость субъектной позиции при стимулировании саморазвития информационно-коммуникационной компетентности студента в системе среднего профессионального образования. Авторы выделяют функции субъектной позиции студента, как своего рода цели формирования информационно-коммуникационной компетентности, такие как: гуманитарная, социальноадаптивная и функция идентификации. Рассматриваются стадии формирования субъектной позиции студента. Исследуется взаимосвязь понятий «субъектность», «саморазвитие» с понятием «информационнокоммуникационная компетентность». В контексте рассматриваемых аспектов раскрывается структура информационно-коммуникационной компетентности в совокупности следующих компонентов: когнитивный, мотивационный и интегративный. Практическая реализация общеметодологического аспекта развития субъектной позиции студента и мотивационного компонента развития конкурентоспособности представляет собой один из актуальных вопросов образовательной практики системы среднего профессионального образования, так как ее результаты углубляют, расширяют и конкретизируют современные представления об информационнокоммуникационной компетентности.

Ключевые слова: информационно-коммуникационная компетентность; среднее профессиональное образование; саморазвитие; субъектность; информационно-образовательная среда; субъектная позиция студента; стимулирование саморазвития студента; колледж; общий методологический аспект; эффективный образовательный процесс.
\end{abstract}

Постоянные изменения, происходящие в системе среднего профессионального образования (СПО) подразумевают сегодня ориентацию на личность студента как субъекта информационно-образовательной среды, обладающего определённым уровнем информационной компетентности. В связи с этим, встаёт вопрос о необходимости разработки организационных установок и теоретических положений развития субъектной позиции информационно-компетентного студента, способствующей развитию конкурентоспособного специалиста, в том числе по специальности СПО 43.02.10 Туризм. Готовность студентов к эффективному применению на практике своих общих и профессиональных компетенций (в том числе и в области информационных технологий), полученных за время обучения в колледже (техникуме), является важнейшей составляющей всей системы СПО, поскольку сегодняшние студенты - это завтрашние специалисты-практики сферы туризма, основой которой является умение грамотно находить, обрабатывать, продавать актуальную информацию, владеть новейшими информационными технологиями при создании турпродукта и его продвижении на рынке туристических услуг. Именно эти качества во многом определяют конкурентоспособность специалиста любого туристского предприятия.

Для организации эффективного образовательного процесса по специальности СПО 43.02.10 Туризм, и систематизации основных направлений подготовки информационно-компетентного специалиста по туризму в системе СПО требуется, как нам представляется, выделить некоторые общеметодологические аспекты, этой подготовки, и в частности, акцентировать внимание на аспекте развития субъектной позиции студента при формировании информационной компетентности и аспекте мотивации конкурентоспособности [1].

Субъектная позиция студента, по мнению В.П. Бедерхановой, формируемая в процессе обучения обеспечивает целостность перманентного профессионально-личностного становления и является обеспечением его успешной профессиональной деятельности [2]. Это утверждение применимо и для подготовки будущих специалистов по туризму в системе СПО, так как они, обучаясь в колледже, обладая своей субъектной точкой зрения и ориентируясь 